\title{
Study on Relaxation Damage Properties of High Viscosity Asphalt Sand under Uniaxial Compression
}

\author{
Yazhen Sun, ${ }^{1}$ Zhangyi Gu, ${ }^{2}$ Jinchang Wang, ${ }^{3}$ Chenze Fang $\mathbb{D},{ }^{1}$ and Xuezhong Yuan $\mathbb{D D}^{2}$ \\ ${ }^{1}$ School of Transportation Engineering, Shenyang Jianzhu University, Shenyang, China \\ ${ }^{2}$ School of Science, Shenyang Jianzhu University, Shenyang, China \\ ${ }^{3}$ Institute of Transportation Engineering, Zhejiang University, Hangzhou, China \\ Correspondence should be addressed to Xuezhong Yuan; yuanxuezhong1@163.com
}

Received 27 November 2017; Revised 24 January 2018; Accepted 28 February 2018; Published 1 April 2018

Academic Editor: Constantin Chalioris

Copyright (C) 2018 Yazhen Sun et al. This is an open access article distributed under the Creative Commons Attribution License, which permits unrestricted use, distribution, and reproduction in any medium, provided the original work is properly cited.

Laboratory investigations of relaxation damage properties of high viscosity asphalt sand (HVAS) by uniaxial compression tests and modified generalized Maxwell model (GMM) to simulate viscoelastic characteristics coupling damage were carried out. A series of uniaxial compression relaxation tests were performed on HVAS specimens at different temperatures, loading rates, and constant levels of input strain. The results of the tests show that the peak point of relaxation modulus is highly influenced by the loading rate in the first half of an L-shaped curve, while the relaxation modulus is almost constant in the second half of the curve. It is suggested that for the HVAS relaxation tests, the temperature should be no less than $-15^{\circ} \mathrm{C}$. The GMM is used to determine the viscoelastic responses, the Weibull distribution function is used to characterize the damage of the HVAS and its evolution, and the modified GMM is a coupling of the two models. In this paper, the modified GMM is implemented through a secondary development with the USDFLD subroutine to analyze the relaxation damage process and improve the linear viscoelastic model in ABAQUS. Results show that the numerical method of coupling damage provides a better approximation of the test curve over almost the whole range. The results also show that the USDFLD subroutine can effectively predict the relaxation damage process of HVAS and can provide a theoretical support for crack control of asphalt pavements.

\section{Introduction}

Relaxation modulus is a main viscoelastic parameter of an asphalt mixture and is used as an important basis for evaluating and analyzing the performance and predicting the long-term stability of a pavement. Therefore, an accurate determination of the relaxation modulus is very important. In general, the time effect in a viscoelastic material is mainly caused by the temperature, the load, the stress level, and the loading pattern. At the stages of construction and operation of a road, the stress level and the loading rate of the asphalt mixture are different. The rheological properties of the asphalt mixture are affected by the temperature, the vehicle load, and the vehicle speed. The stress in the pavement gradually dissipates with the passage of time, and stress relaxation occurs. When the temperature is very high, the stress accumulated in the pavement will dissipate quickly because of the stronger relaxation ability. However, when the temperature is lower, the stress accumulated in the pavement will dissipate slowly because of the poor relaxation ability, and cracks may occur when the final stress is greater than the ultimate strength of the material [1]. It is necessary to study the viscoelastic properties of asphalt mixtures by relaxation tests in order to control the development of this disease in pavements.

Since the pioneering work of stress relaxation [2], there has been an increase of interest in this field [3-6]. Nowadays, there are two popular solutions for the determination of the relaxation modulus, one method is through the relaxation tests (the direct method) and another method is by the interconversion from the creep compliance (the indirect method) [7]. Hopkins and Hamming [8] discretized the time domain and established an iterative expression between the relaxation modulus and the creep compliance which was obtained from creep tests and can be transformed to relaxation modulus. However, the indirect 
method is comparatively complicated [9]. In the past, stress relaxations were researched mainly through uniaxial tension tests and bending tests. In fact, the pavement surface of asphalt concrete is generally subjected to compression load. Now, a direct compression relaxation test can be carried out with the improvement of experimental technologies, with its loading pattern being analogue to the actual loading pattern. Hence, a reliable analytical solution for the determination of the relaxation modulus by uniaxial compressive relaxation tests with high viscosity asphalt sand (HVAS) is proposed in this paper. As suggested in the literatures, the direct compression relaxation modulus tests were carried out to get more accurate relaxation modulus.

There are initial cracks and voids in the asphalt mixture, which leads to the deterioration and damage of the materials. For such heterogeneous material as the asphalt mixture, the statistical Weibull damage model was used to reflect the deterioration of the asphalt mixture [10], and the damage probability of the asphalt mixture was described by the Weibull function [11]. Although ABAQUS provides a large number of unit libraries and solving models for users, it is inevitable that the general software is deficient in some certain fields. In view of this, ABAQUS provides a large number of user-defined subroutines to define the model [12]. During the secondary development of the UMAT subroutine, Yang [13] compiled the Mohr-Coulomb interface subroutine basing on the Rankine criterion. The results are consistent with the FLAC-3D calculation results, which indicate that the subroutine is of great value in guiding engineering practice. Fu [14], on the basis of the user material subroutine provided by UMAT, developed a modified Burgers creep model subroutine. It was proved that the subroutine could distinguish the viscoelastic deformation of the asphalt mixture correctly and made up for the deficiency of ABAQUS creep model [15]. Although the above researches demonstrate that the UMAT subroutine performs well in the fields of compression creep, the subroutine needs to determine the stress increment matrix, so the compilation process is rather complicated. With the aid of a simpler interface subroutine USDFLD (user subroutine to redefine field variables at a material point), the ABAQUS GMM is more suitable for a secondary development, which is used in the simulation of stress relaxation in this paper.

\section{Experimental Program}

2.1. Theory. Direct compression relaxation tests, at constant levels of input strain, were carried out on the specimens. The definition of the constant level of input strain at a given time $t$ is

$$
\mathcal{\varepsilon}= \begin{cases}0 & t<0 \\ \varepsilon_{0} & t \geq 0\end{cases}
$$

Due to the relaxation nature of the HVAS, the magnitude of the deformation is constant according to the preset program. Then the relaxation modulus can be calculated as
TABLE 1: Gradation.

\begin{tabular}{lc}
\hline Sieve size $(\mathrm{mm})$ & Passing percentage \\
\hline 9.5 & 100 \\
4.75 & 80.4 \\
2.36 & 45.2 \\
1.18 & 35.3 \\
0.6 & 22.2 \\
0.3 & 17.3 \\
0.15 & 12.4 \\
0.075 & 7.6 \\
\hline
\end{tabular}

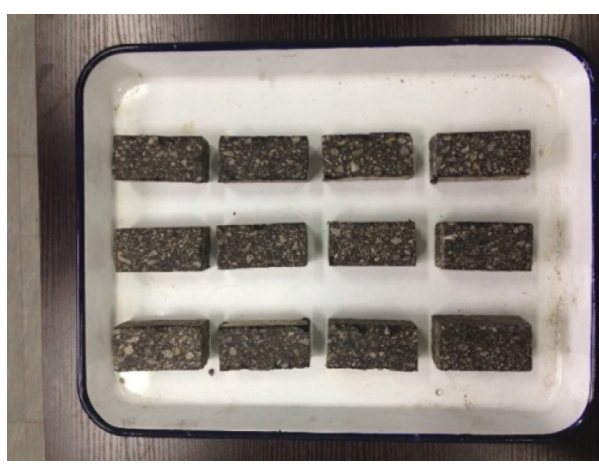

Figure 1: Prism specimen.

$$
E(t)=\frac{F}{A \cdot \varepsilon_{0}},
$$

where $F$ is the load $(\mathrm{kN}), \varepsilon_{0}$ is the constant level of input strain, and $A$ is the cross-sectional area of the specimen $\left(\mathrm{mm}^{2}\right)$.

2.2. Material Properties. A 70 penetration bitumen was used as asphalt binder for preparations of the specimens. Limestone was used as the aggregates. The ratio of binder to aggregates is $8.1 \%$ by weight. The continuous aggregate gradation, having the nominal maximum size of $10 \mathrm{~mm}$, is listed in Table 1. An additional 1\% activated rubber crumb and $0.7 \%$ TCA additive of the mass of asphalt mixture were added during the blending process.

2.3. Specimen Preparations. Track plate specimens manufactured by wheel rolling which agree with the standard test method [16] were cut into small beams with the dimensions of $30 \times 35 \times 250 \mathrm{~mm}^{3}$.

As confirmed by the previous research, the specimen was proposed to be cylinder or nearly cube prism [15]. Since the desirable height to diameter ratio of a specimen was 2 [17], each beam was cut into $30 \times 35 \times 70 \mathrm{~mm}^{3}$ prism specimens to reduce the size effect. The specimens were polished to reduce the error in the loading area, as shown in Figure 1. During the polishing, the air blew continuously on the surface to help remove the debris generated.

2.4. Determination of Constant Levels of Input Strain for Relaxation Tests. Before the relaxation tests, the uniaxial 


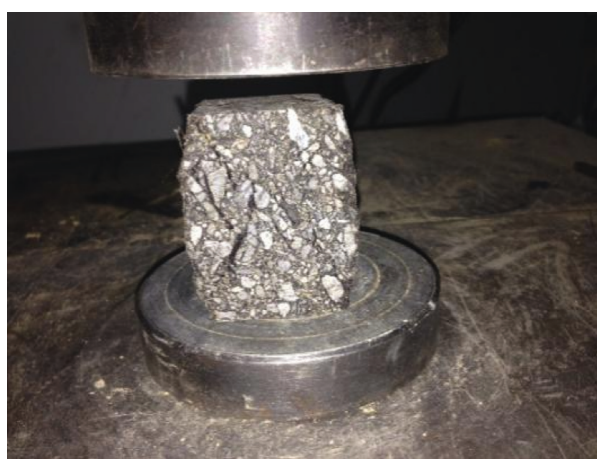

(a)

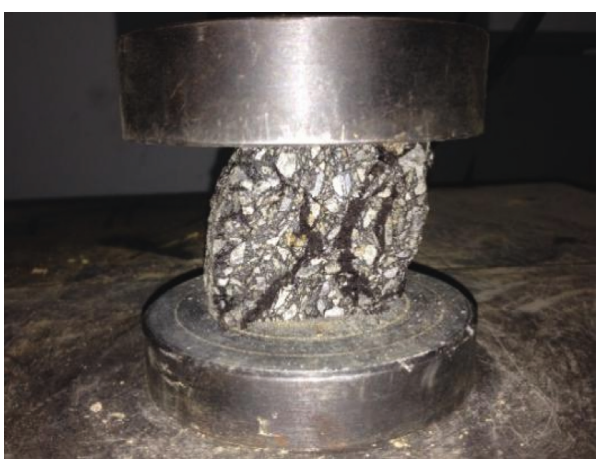

(b)

FIgURE 2: Diagonal failures of specimens under compression.

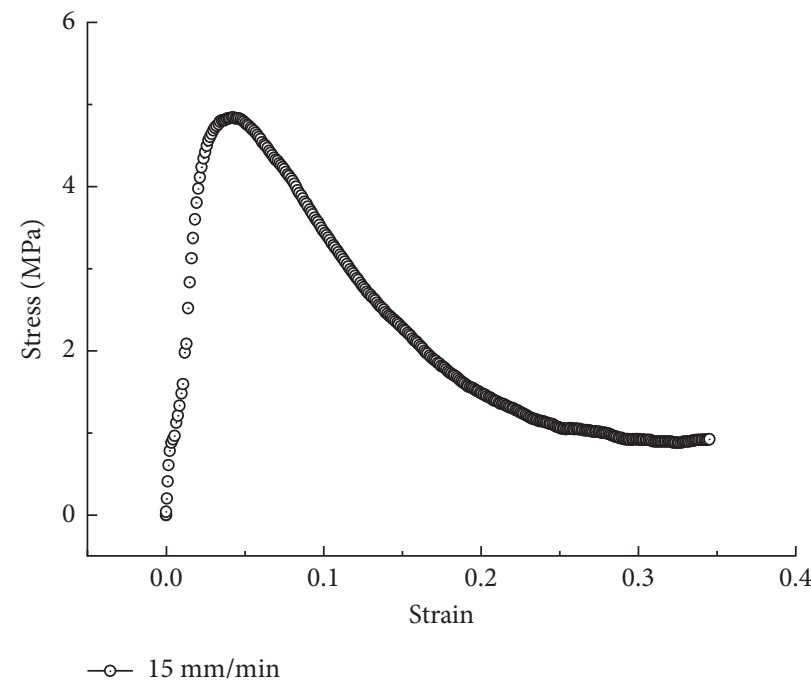

(a)

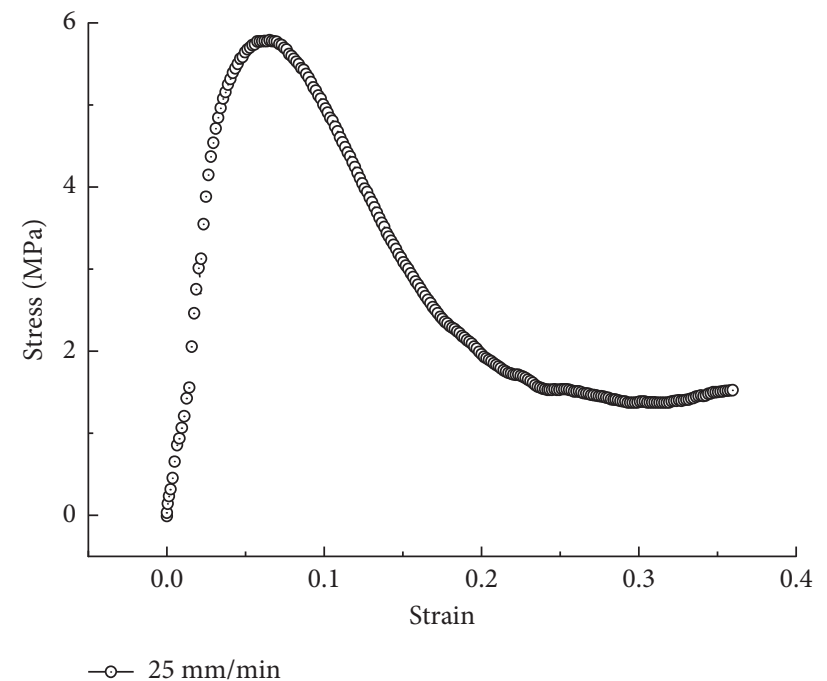

(b)

Figure 3: Stress-strain diagrams at different loading rates at $15^{\circ} \mathrm{C}$. (a) $15 \mathrm{~mm} / \mathrm{min}$. (b) $25 \mathrm{~mm} / \mathrm{min}$.

compression strength tests were carried out, and the diagonal failures of specimens under compression are shown in Figure 2.

The stress-strain data of the compression failure tests at different loading rates were collected, and the diagrams are shown in Figure 3.

The constant level of input strain is a key parameter in the relaxation test. It should be noted that, in the uniaxial relaxation test, there was no standard evaluation method for defining the constant level of input strain until Walubita et al. [18] proposed that $20 \%$ of the maximum strain in a compressive test should be defined as the input strain. The constant level of input strain was calculated to characterize the viscoelastic behaviour of the HVAS within the undamaged limit. In general, it is widely accepted that the specimens are not damaged before the peak point of the stress-strain diagram. During the relaxation experiment, when the constant level of input strain varied from low to high, the property of the asphalt mixture changed from linear viscoelasticity to viscoplasticity [19]. Under the small-strain condition, the specimen was assumed to be not damaged (the strain level was within the linearly viscoelastic range), so the constant level of input strain was conservatively assigned 10\% of the strain at the maximum stress in our experiment. The corresponding displacement at the maximum stress, at the loading rates of $15 \mathrm{~mm} / \mathrm{min}$ and $25 \mathrm{~mm} / \mathrm{min}$, respectively, was obtained from Figure 3 as $3.003 \mathrm{~mm}$ and $4.053 \mathrm{~mm}$, respectively. The input displacements were set at $0.3 \mathrm{~mm}$ and $0.4 \mathrm{~mm}$, respectively, after the rounding off.

2.5. Uniaxial Compression Relaxation Tests. The stress relaxation test is an experimental method for the determination of the viscoelastic parameters of materials, which is commonly used to evaluate the stress relaxation properties of materials. The stress response depends on the loading history as the viscoelastic material has the memory effect. Hence, the effects of loading process on the relaxation modulus were investigated. The direct compression relaxation modulus tests, at five constant levels of input strain of 0.004285 , $0.012857,0.021428,0.042857$, and 0.085714 (corresponding to the input displacements of $0.3 \mathrm{~mm}, 0.9 \mathrm{~mm}, 1.5 \mathrm{~mm}$, 
$3 \mathrm{~mm}$, and $6 \mathrm{~mm}$ ), four temperatures of $15^{\circ} \mathrm{C},-5^{\circ} \mathrm{C},-15^{\circ} \mathrm{C}$, and $-25^{\circ} \mathrm{C}$, four loading rates of $5 \mathrm{~mm} / \mathrm{min}, 15 \mathrm{~mm} / \mathrm{min}$, $25 \mathrm{~mm} / \mathrm{min}$, and $50 \mathrm{~mm} / \mathrm{min}$, were conducted on each specimen; thus, a total of 144 tests were performed. After the specimen was put into the environmental chamber, the temperature was increased to the expected value. In order to reach thermal equilibrium inside the specimen, it should be conditioned for 4 hours or more. Vaseline was applied on the surface of the sample to reduce the friction and the boundary effect. The specimen was placed between the pressure head and the base of a WDW universal material testing machine, and then the constant level of input strain was applied.

\section{Test Results and Analysis}

3.1. Compression Relaxation Tests at $15^{\circ} \mathrm{C}$. Figure 4 shows the effects of the loading rates on the relaxation moduli at $15^{\circ} \mathrm{C}$ as the input strain varies from 0.004228 to 0.08571 .

As shown in Figure 4, the relaxation modulus of the HVAS at $15^{\circ} \mathrm{C}$ has an L-shaped curve over a wide range of time, and the modulus decreases sharply in the first half of the curve and then remains nearly constant in the second half. The L-shaped curve also agrees with the relaxation properties very well. During the test (Figures 4(a) and 4(b)), when the constant level of input strain was relative small, no obvious deterioration was observed in the specimen. As the loading rate increases, the speed of stress accumulated exceeds than that of dissipation, which leads to the increase of the peak point of the relaxation modulus. The peak point of relaxation modulus is highly influenced by the loading rate in the first half of the L-shaped curve, while the relaxation modulus is almost constant in the second half of the curve. The effect of the loading rate on the peak point of the relaxation curve is obvious with a larger constant level of input strain. When the input strain is less than 0.012857 (Figure 4 (a)), the peak point of the relaxation modulus increases proportionally to the loading rate because the material is in the elastic stage. However, when the input strain is larger (Figures 4(c)-4(e)), the peak point does not increase proportionally to the loading rate, and at $50 \mathrm{~mm} / \mathrm{min}$ loading rate, it is not even the maximum modulus because the material is in the plastic stage.

In the first half of the L-shaped curve, the relaxation modulus increases with the input strain (Figures 4(a)-4(d)). However, comparing Figures 4(d) and 4(e), when the input strain exceeds 0.042857 , the peak point of the relaxation modulus decreases with higher input strain because the material is in the plastic stage. This fact confirmed that the damage of the specimen contributes to the decrease of the relaxation modulus because the stress exceeds the linear viscoelastic limit.

3.2. Compression Relaxation Tests at $-5^{\circ} \mathrm{C}$. The variation tendencies of the relaxation moduli of the HVAS, at a test temperature of $-5^{\circ} \mathrm{C}$, are similar to the previous tests, but the relaxation moduli increase significantly at the same loading rates and the constant levels of input strains, as shown in Figure 5 . The capacity of relaxation can be expressed by the rate of change of the relaxation modulus; the higher the rate of change, the stronger the relaxation capacity. Comparing the two groups of the graphs of the effects at $15^{\circ} \mathrm{C}$ and $-5^{\circ} \mathrm{C}$ (Figures 4 and 5), the HVAS has a poor relaxation capacity at $-5^{\circ} \mathrm{C}$, and this is resulted from the low temperature, at which the stress has accumulated significantly. For example, as shown in Figures 4(d) and 5(d), when the input stain is 0.042857 at the loading rate of $25 \mathrm{~mm} / \mathrm{min}$, the variation of the relaxation modulus is $4400 \mathrm{MPa}$ at $15^{\circ} \mathrm{C}$ and $2000 \mathrm{MPa}$ at $-5^{\circ} \mathrm{C}$, respectively, and we say that the HVAS has a poor relaxation capacity at $-5^{\circ} \mathrm{C}$. If the input strain exceeds 0.042857 , both the relaxation moduli are decreased instead of increasing. This is not surprising because of the emerging of damage of the HVAS.

3.3. Compression Relaxation Tests at $-15^{\circ} \mathrm{C}$. Compared with $-5^{\circ} \mathrm{C}$, the peak point of the relaxation modulus decreases as the constant level of input strain is just over 0.012857 . This can be explained that the superposition of the stresses caused by the applied load and temperature results in a greater stress, which leads to the damage and consequently the decrease of the relaxation modulus, as shown in Figure 6. Meanwhile, the damage occurs and the extent of damage is dependent on the input strain. Under the continuous growth of the loading rate and the input strain, the failure of the HVAS prism is inevitable, and it is not necessary to complete the remaining test according to the plan.

3.4. Compression Relaxation Tests at $-25^{\circ} \mathrm{C}$. As shown in Figure 7 , the deterioration of the sample occurs at the constant level of input strain of 0.021428 . In addition, comparing with $-15^{\circ} \mathrm{C}$, the peak point of the relaxation modulus decreases as the input strain is 0.01285 . This indicates that the damage of the HVAS shifts to an earlier stage. So, as the temperature drops, the damage occurs earlier.

The relaxation tests could be completed at the constant levels of input strain that ranges from 0.042857 to 0.085714 at temperatures above $-5^{\circ} \mathrm{C}$; however, obvious deterioration was observed in the specimen when the input strain is only 0.042857 at temperature below $-5^{\circ} \mathrm{C}$, and the test came to an end. Because the determination of the relaxation modulus is highly sensitive to the temperature, it is suggested that for the HVAS relaxation tests, the temperature should be no less than $-15^{\circ} \mathrm{C}$.

\section{Determination of Model Parameters}

Mechanical models may be considered as different combinations of linear spring(s) and linear dashpot(s) in various series and/or parallel arrangements depending upon the complexity of viscoelastic material behaviour. These basic elements and their combinations allow the modelling of the viscoelastic behaviour of asphalt mixtures and binders better than the empirical mathematical models. The linear spring responds the same as a linear elastic material, while the basic response of a linear dashpot is the same as that of a Newtonian fluid. Combining these two basics in various series 


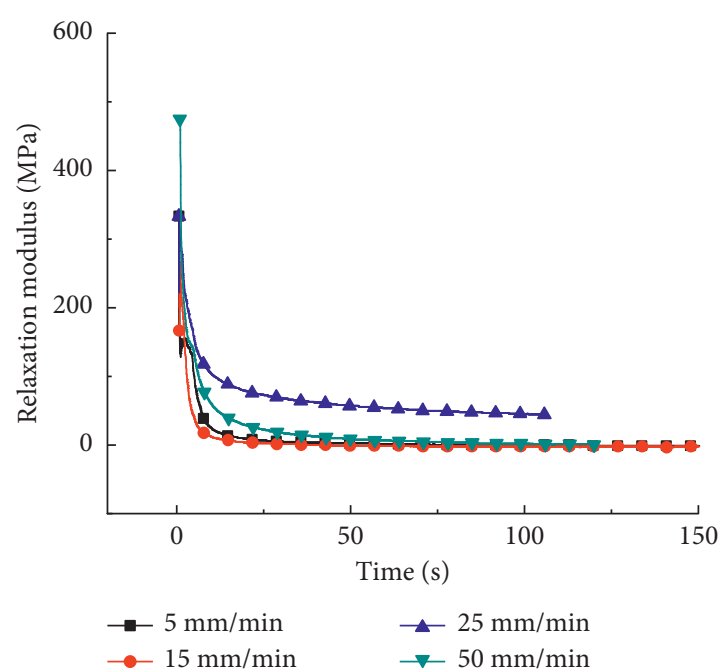

(a)

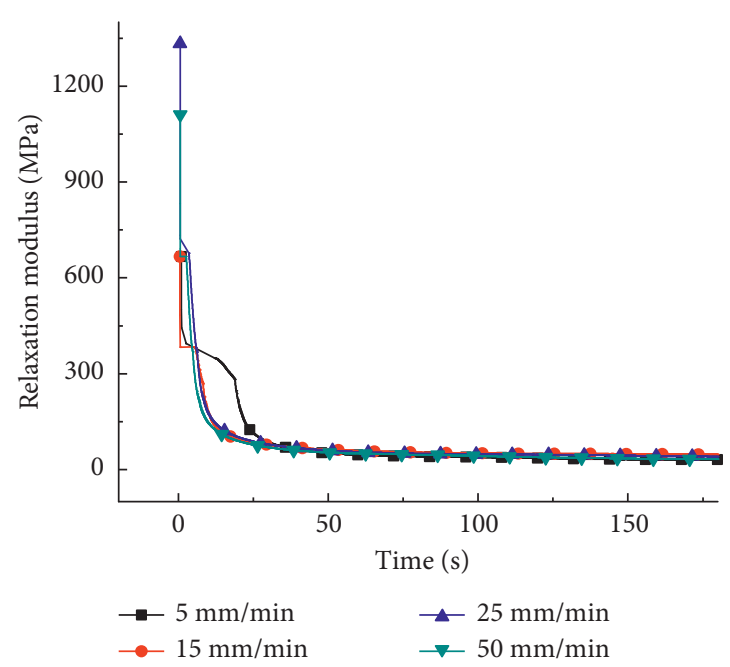

(c)

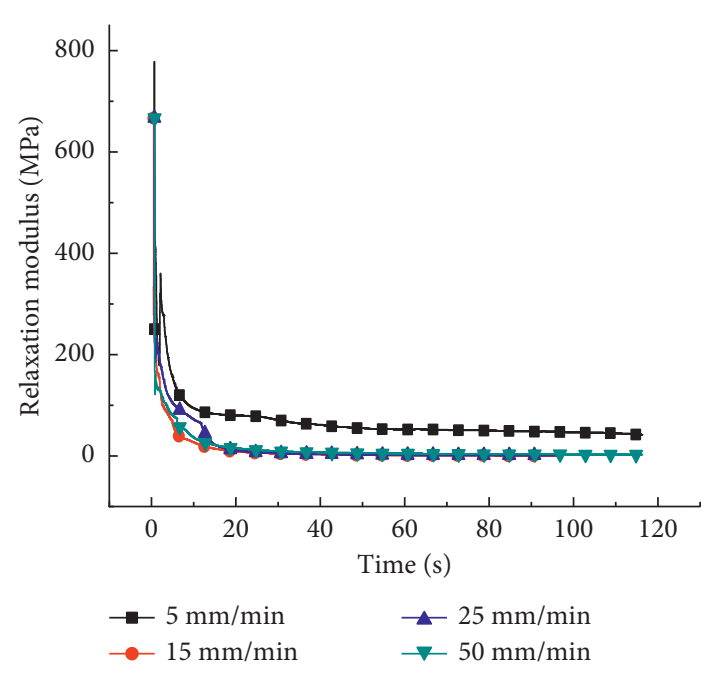

(b)

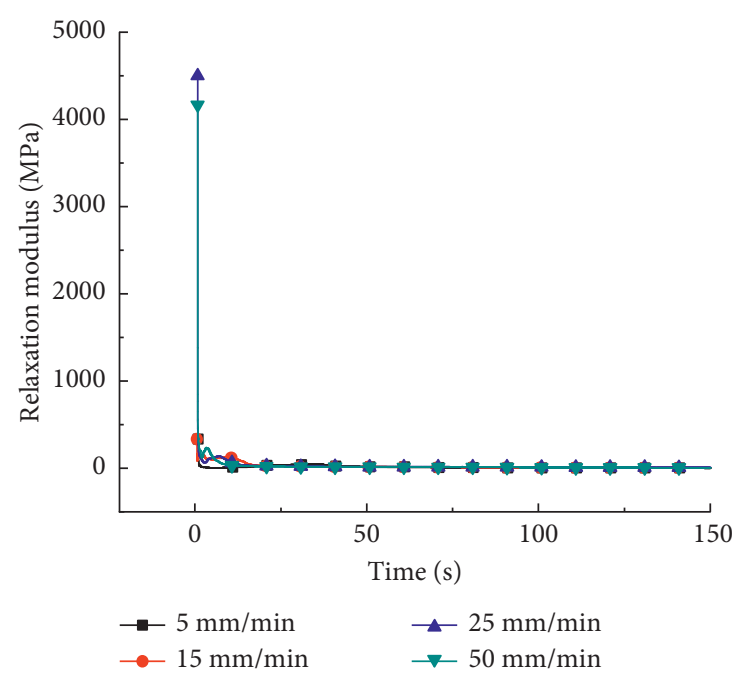

(d)

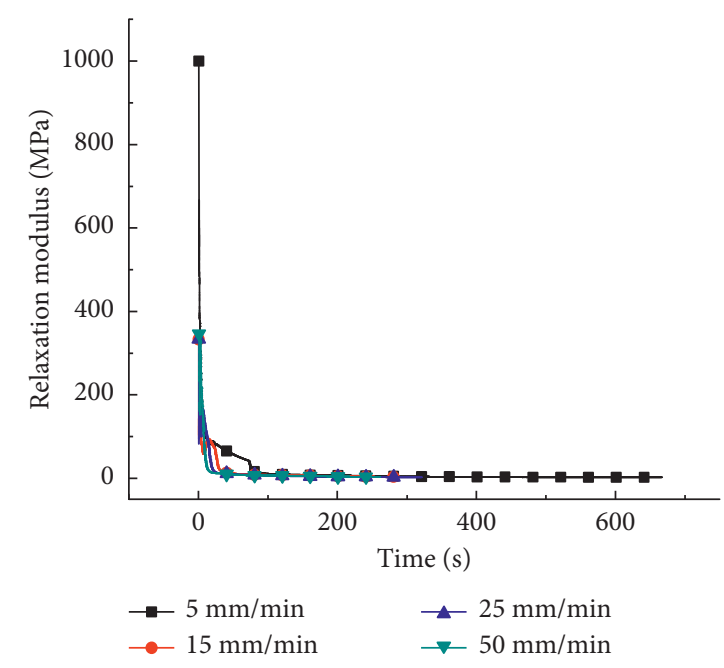

(e)

FiguRE 4: Effects of different loading rates and constant levels of input strain on relaxation moduli at $15^{\circ} \mathrm{C}$. (a) 0.004285 . (b) 0.012857 . (c) 0.021428 . (d) 0.042857. (e) 0.08571 . 


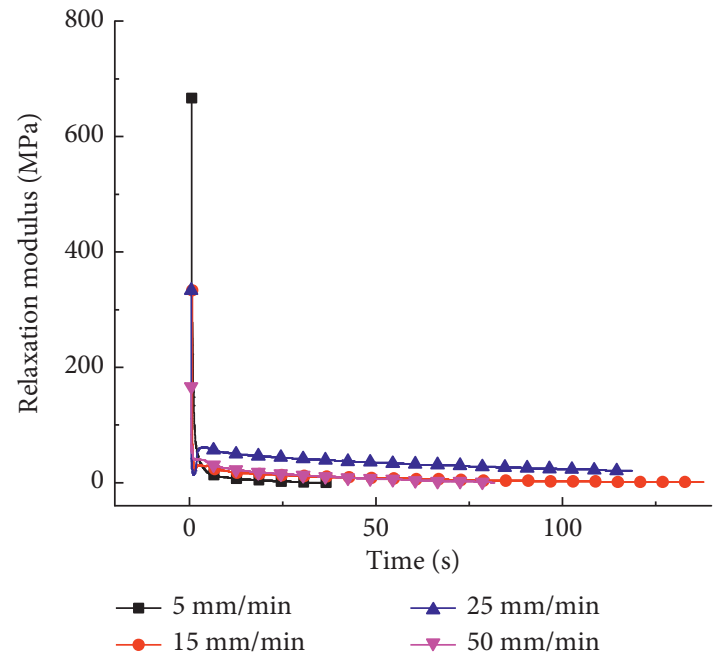

(a)

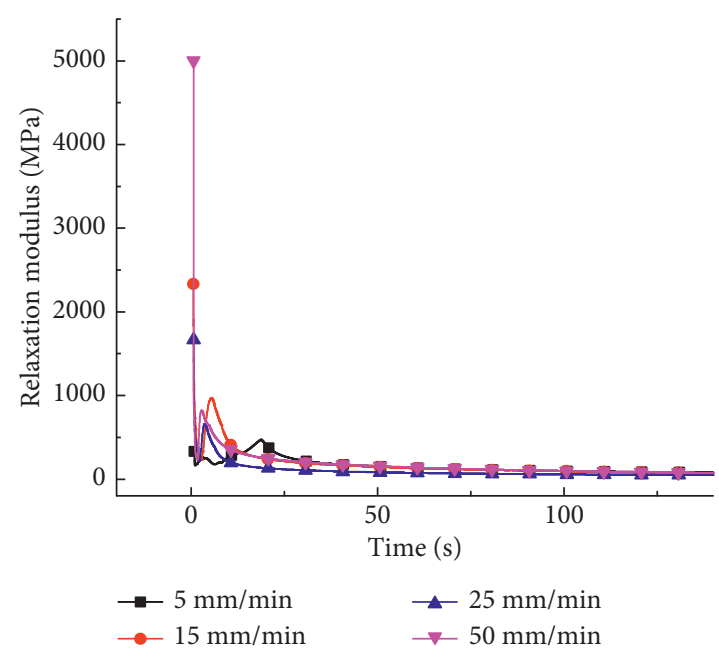

(c)

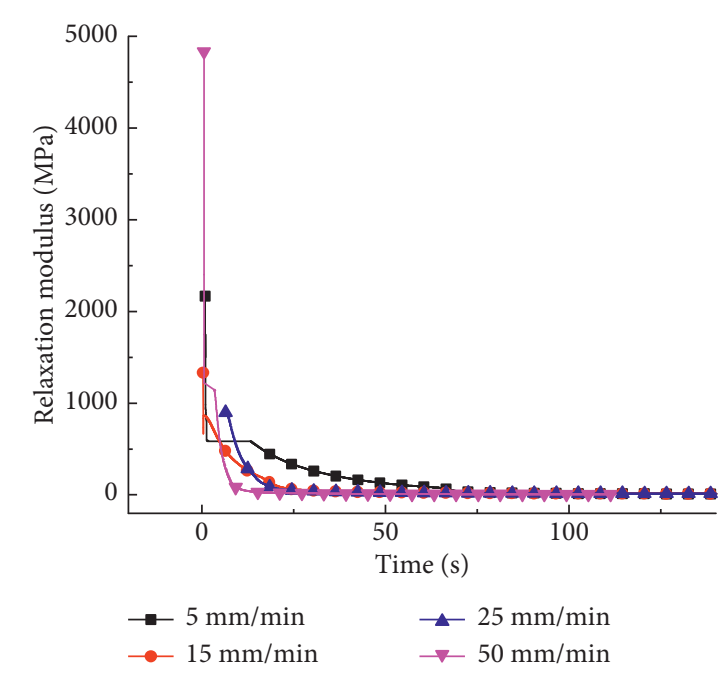

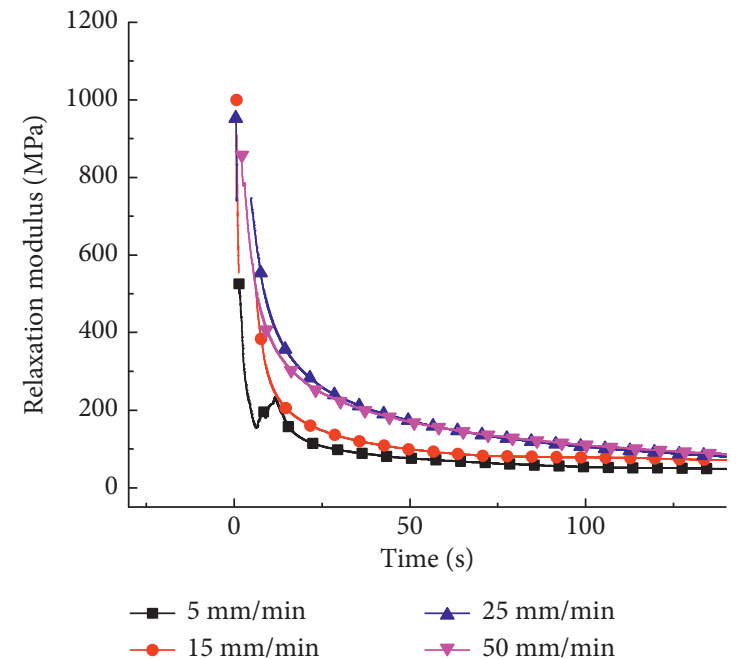

(b)

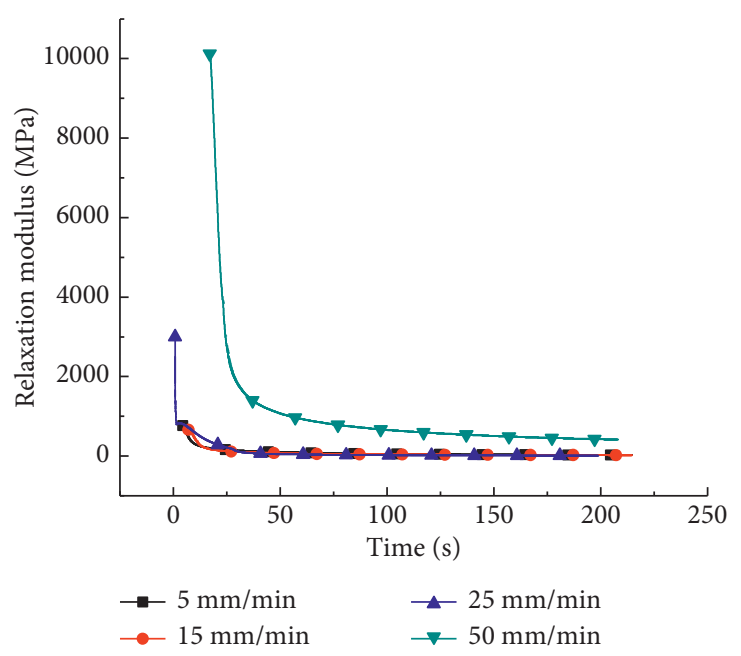

(d)

(e)

FIGURE 5: Effects of different loading rates and constant levels of input strains on relaxation moduli at $-5^{\circ} \mathrm{C}$. (a) 0.004285 . (b) 0.012857 . (c) 0.021428. (d) 0.042857. (e) 0.085711. 


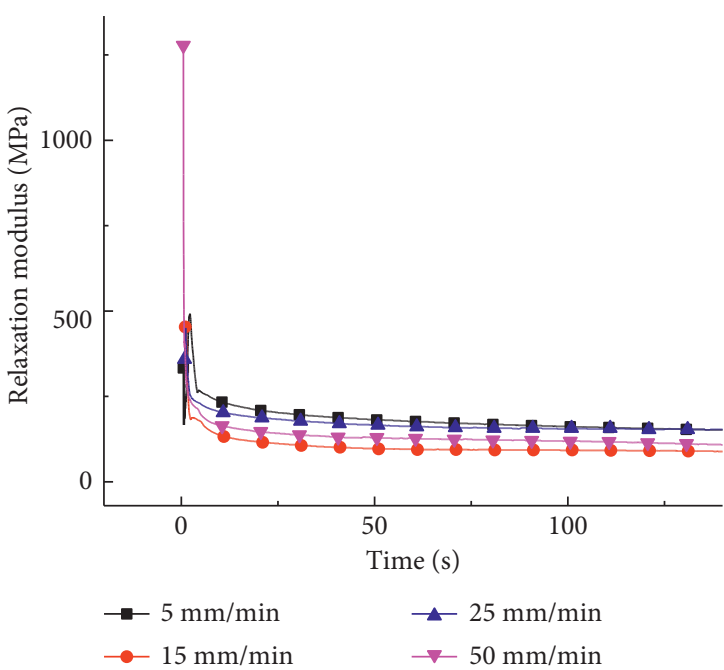

(a)

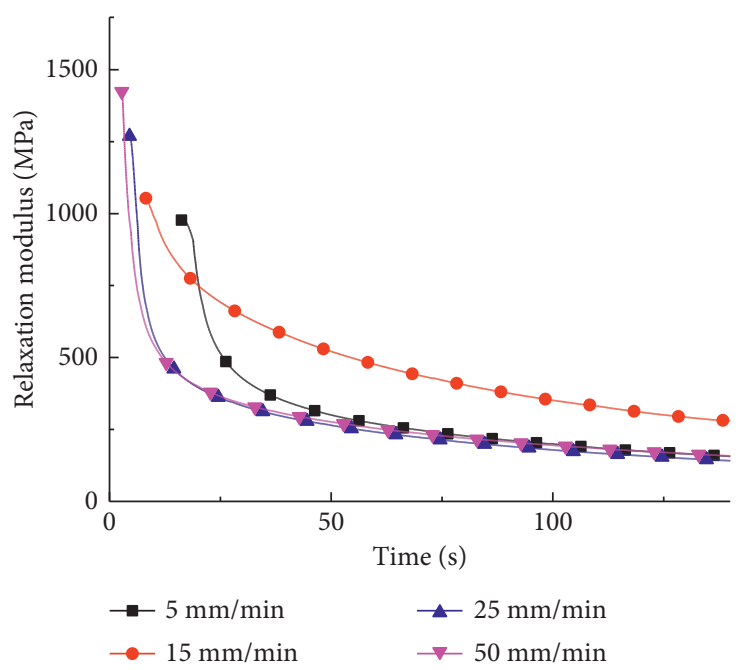

(c)

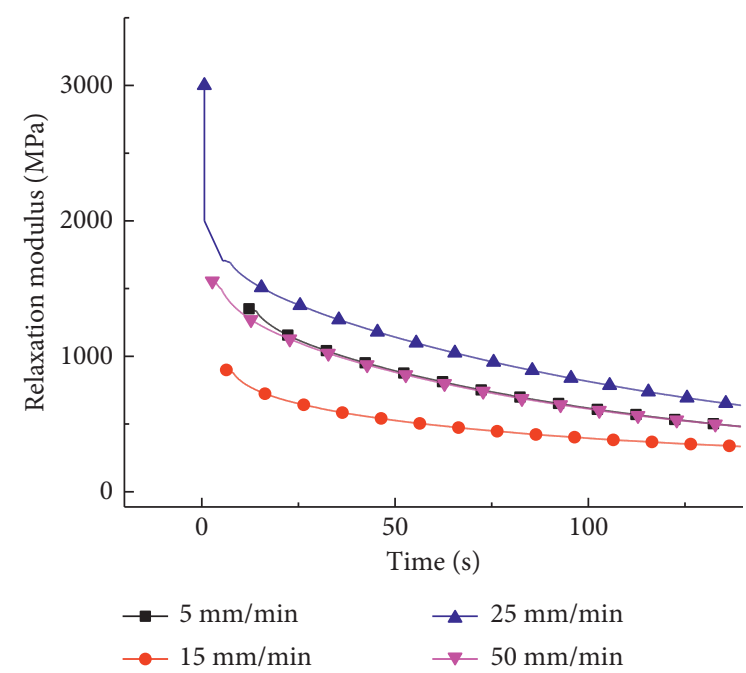

(b)

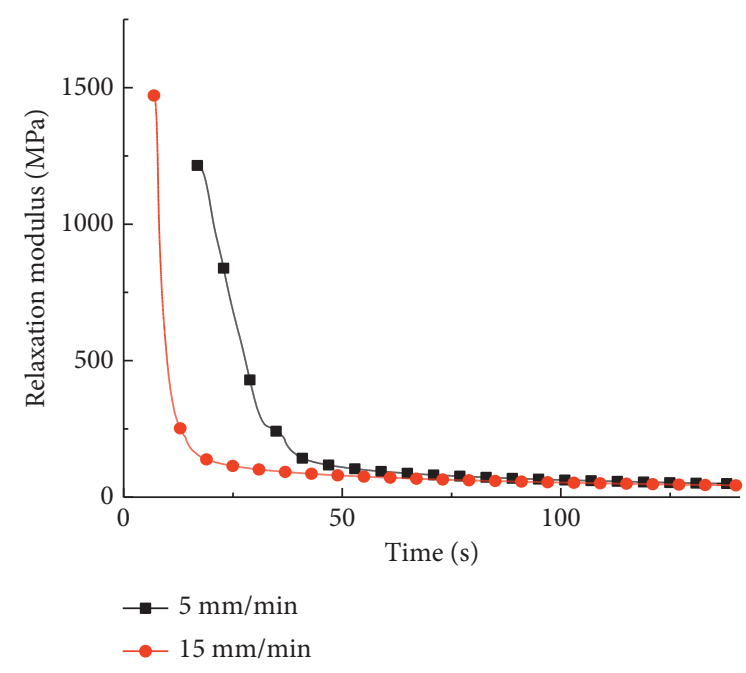

(d)

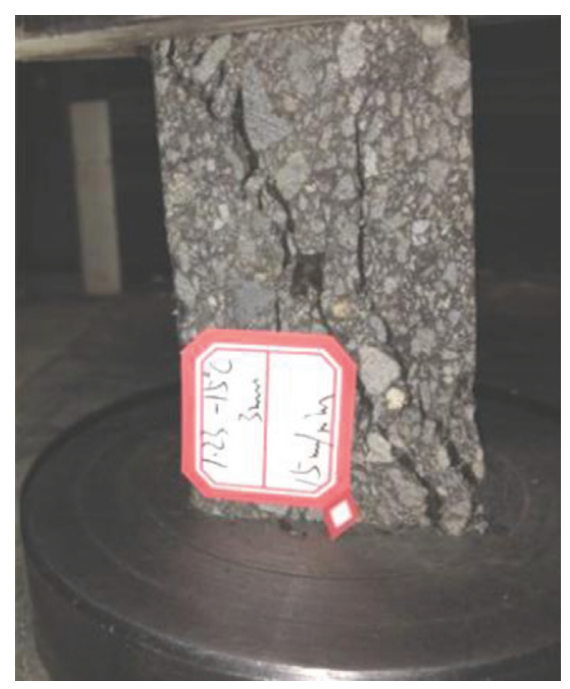

(e)

FIGURE 6: Effects of different loading rates and constant levels of input strain on the relaxation moduli at $-15^{\circ} \mathrm{C}$. (a) 0.004285. (b) 0.012857 . (c) 0.021428. (d) 0.042857. (e) Specimen damages at $-15^{\circ} \mathrm{C}$. 


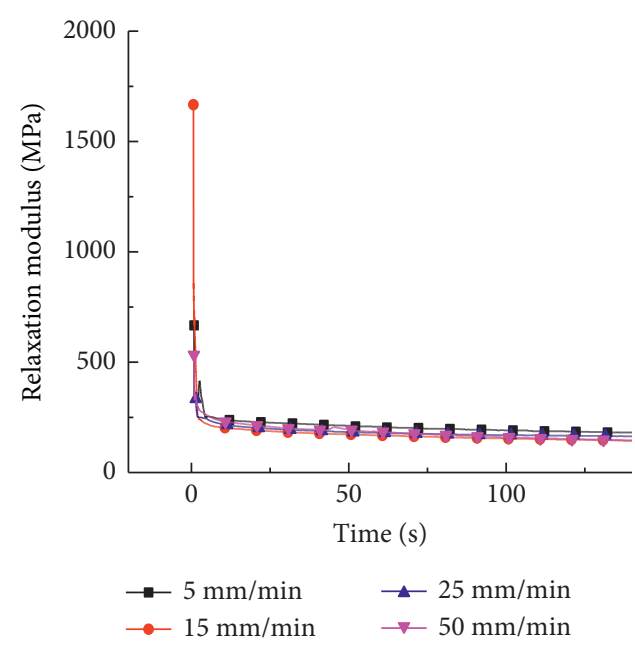

(a)

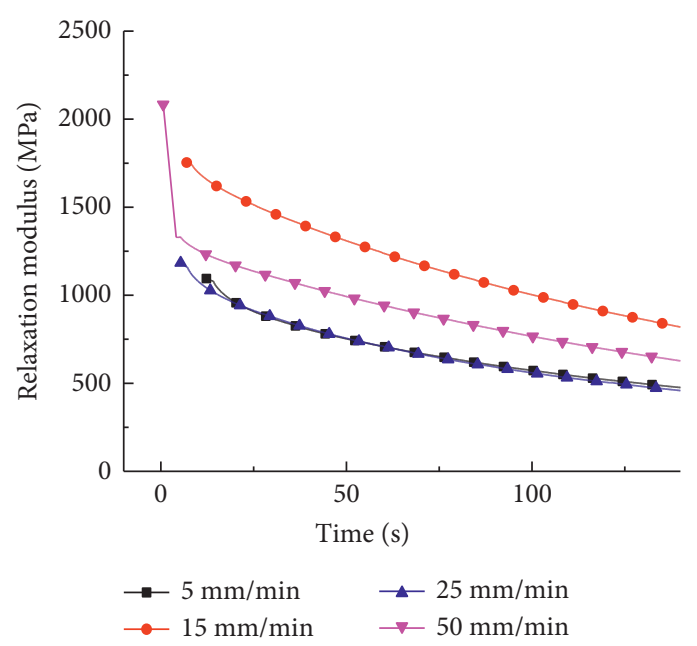

(b)

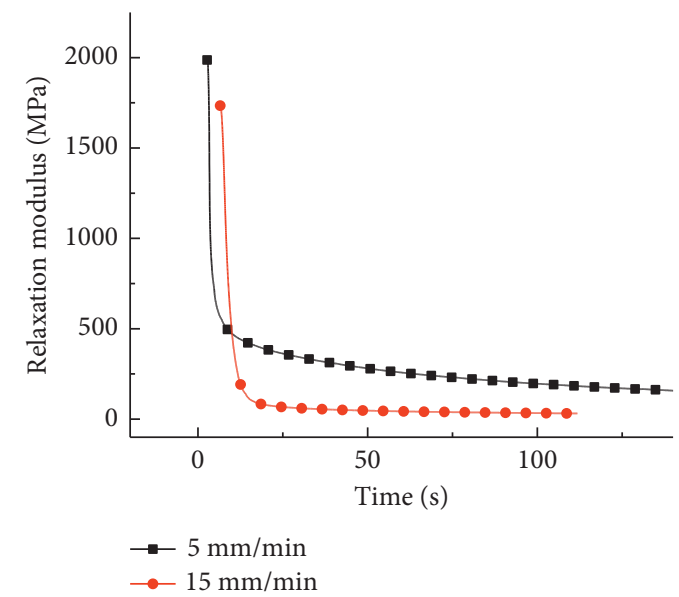

(c)

Figure 7: Effects of different loading rates and constant levels of input strain on relaxation moduli at $-25^{\circ} \mathrm{C}$. (a) 0.004285 . (b) 0.012857 . (c) 0.021428 .

and/or parallel arrangements produces the viscoelastic mechanical models, some of which, for example, Maxwell model and Kelvin model, are too simple to adequately model the actual behaviour of asphalt mixtures, while some other ones, for example, generalized models, may properly capture the actual behaviour of asphalt mixtures. The GMM appears to be the best phenomenological representation of the relaxation behaviour for HVAS [20].

The relaxation modulus $E(t)$ of the HVAS can be calculated by employing GMM [21]:

$$
E(t)=\sum_{i=1}^{n} E_{i} e^{-t / \tau_{\mathrm{i}}},
$$

where $E_{i}$ is the modulus for a single Maxwell model, $t$ is the time, $\tau_{i}$ is the relaxation time, and $n$ is the number of elements for the GMM.

In agreement with the earlier results [22], the precision of the characterization of the viscoelastic behaviour varies with the number of GMM units, so $2,4,6$, and 8 arms of GMM were used to fit the relaxation modulus at different temperatures. An example is provided at the constant level of the input strain of 0.004285 and a loading rate of $50 \mathrm{~mm} / \mathrm{min}$, as listed in Table 2 .

As shown in Table 2, the $R^{2}$ value of the GMM increases with the number of units from 2 to 6 . However, the $R^{2}$ value decreases as the number of units increases from 6 to 8 , so the GMM with 6 arms was used to characterize the relaxation of the HVAS.

Although the model parameters can express the relaxation properties of the HVAS, the more detailed damage behaviour is not depicted yet. So, there is still room for further study of the relaxation damage model.

\section{USDFLD Development and Verification of HVAS Relaxation Damage}

Relaxation often plays a crucial role in the rheological properties, so it is very important to carry out the accurate reliability analysis of the change law of the relaxation modulus. Initially, the GMM in the ABAQUS model library is used to determine the viscoelastic responses without 
TABle 2: GMM parameters at $15^{\circ} \mathrm{C}$.

\begin{tabular}{lcccc}
\hline \multirow{2}{*}{ Model parameter } & \multicolumn{5}{c}{ Number of units } \\
& 2 & 4 & 6 & 8 \\
\hline$E_{1}(\mathrm{MPa})$ & 182.072 & 2.004 & 1.493 & 15.261 \\
$E_{2}(\mathrm{MPa})$ & 1125.975 & 10.042 & 5015.853 & 15.261 \\
$E_{3}(\mathrm{MPa})$ & - & 18.491 & 41.397 & 41.927 \\
$E_{4}(\mathrm{MPa})$ & - & 295.548 & 18.603 & 15.199 \\
$E_{5}(\mathrm{MPa})$ & - & - & 157.825 & 1.214 \\
$E_{6}(\mathrm{MPa})$ & - & - & 1.409 & 1.214 \\
$E_{7}(\mathrm{MPa})$ & - & - & - & 1.214 \\
$E_{8}(\mathrm{MPa})$ & - & - & - & 15.199 \\
$\tau_{1} / \mathrm{s}$ & 10.737 & 6.707 & $4.604 \mathrm{e} 21$ & 2.433 \\
$\tau_{2} / \mathrm{s}$ & 0.646 & 39.878 & 1.264 & 2.433 \\
$\tau_{3} / \mathrm{s}$ & - & 80.755 & 26.342 & 11.278 \\
$\tau_{4} / \mathrm{s}$ & - & 5.628 & 1.435 & 2.433 \\
$\tau_{5} / \mathrm{s}$ & - & - & 6.398 & 2.436 \\
$\tau_{6} / \mathrm{s}$ & - & - & $1.715 \mathrm{e} 21$ & 2.436 \\
$\tau_{7} / \mathrm{s}$ & - & - & - & 2.437 \\
$\tau_{8} / \mathrm{s}$ & - & - & - & 2.433 \\
$R^{2}$ & 0.9769 & 0.9896 & 0.9986 & 0.9886 \\
\hline
\end{tabular}

TABle 3: Damage thresholds at different constant levels of input strain at $15^{\circ} \mathrm{C}$.

\begin{tabular}{lccccc}
\hline Input strain & 0.004285 & 0.012857 & 0.021428 & 0.04285 & 0.08571 \\
\hline $\begin{array}{l}\text { Damage } \\
\text { threshold }\end{array}$ & 0.0041 & 0.0093 & 0.017 & 0.021 & 0.047 \\
\hline
\end{tabular}

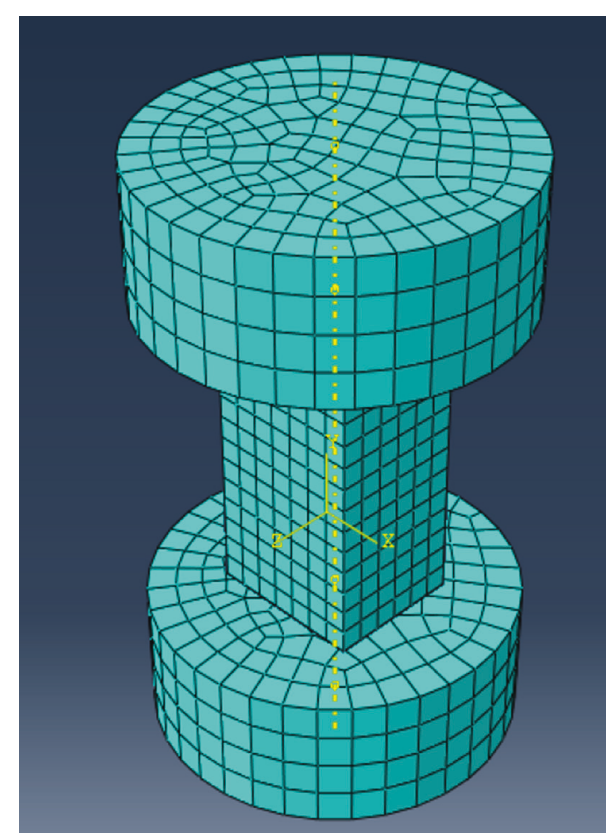

Figure 8: Diagram of the model mesh.

associating with the damage while the relaxation behaviour is strongly dependent on the viscoelastic damage. In order to study the relaxation damage property, a modified GMM relaxation damage model was established with the USDFLD subroutine. With the new development modified GMM relaxation damage model in ABAQUS, numerical simulations of uniaxial compression relaxation tests were carried out.
TAble 4: Prony parameters at $15^{\circ} \mathrm{C}$.

\begin{tabular}{lccccc}
\hline Model & \multicolumn{5}{c}{ Input strain } \\
parameter & 0.004285 & 0.01285 & 0.021428 & 0.04285 & 0.08571 \\
\hline$E_{1}$ & $5.44 E-08$ & 0.5334 & 0.690846 & $2.14 E-05$ & 0.15845 \\
$E_{2}$ & 0.000182 & 0.2115 & 0.014715 & 0.11 & 0.27840 \\
$E_{3}$ & $1.50 E-06$ & 0.1214 & 0.104812 & 0.1067 & 0.13184 \\
$E_{4}$ & $6.782 E-07$ & 0.0809 & 0.054306 & 0.01099 & 0.07601 \\
$E_{5}$ & $5.754 E-06$ & 0.0303 & 0.051410 & 0.7688 & 0.07601 \\
$E_{6}$ & $5.137 E-08$ & 0.0202 & 0.08353 & $1.76 E-06$ & 0.27828 \\
$\tau_{1} / \mathrm{s}$ & $4.604 e 21$ & 32.12 & 23.4 & 1 & 1 \\
$\tau_{2} / \mathrm{s}$ & 1.264 & 191.37 & 1.52 & 18.84 & 3.16 \\
$\tau_{3} / \mathrm{s}$ & 26.342 & 986.68 & 436.43 & 18.84 & 19.5 \\
$\tau_{4} / \mathrm{s}$ & 1.435 & 7549.62 & 3.53 & 1 & 286.09 \\
$\tau_{5} / \mathrm{s}$ & 6.398 & 129.321 & 65.88 & 7.422 & 296.14 \\
$\tau_{6} / \mathrm{s}$ & $1.715 e 21$ & 3839104 & 6792.17 & 18.84 & 3.16 \\
\hline
\end{tabular}

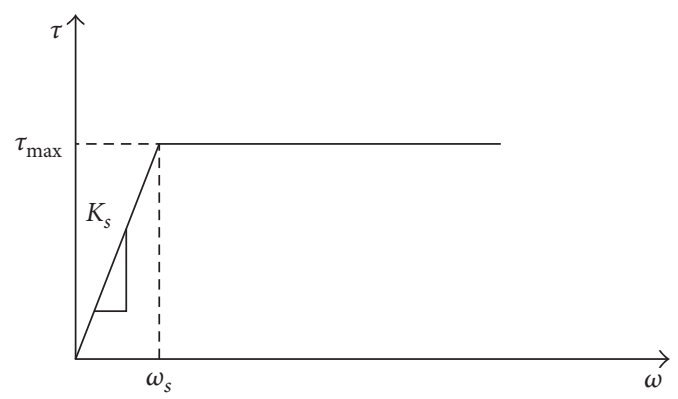

Figure 9: Elastic-plastic Coulomb friction model.

5.1. Applications of USDFLD Subroutine in Damage Relaxation. The ABAQUS built-in models have some limitations due to the fact that there are no coupling damage parameters in the models, so a modified GMM model is proposed. Firstly, the constitutive model suitable for the asphalt mixture was selected, and a USDFLD user subroutine was written by FORTRAN language to establish the correction model of coupling damage. Based on the ABAQUS software platform, not only the secondary development of the GMM constitutive model is realized, but also the damage mechanism is embedded. The subroutine is invoked by a call function in the calculation process. Some known parameters are passed by the ABAQUS main program, combined with the generalized Hooke law, to calculate the test strain, which is used to determine whether the strain exceeds the threshold value of damage, and the choice of the appropriate calculation method. Secondly, using the compiled USDFLD subroutine, a 3-D finite element model was established to study the damage relaxation behaviour of the HVAS, and the performance of the linear viscoelastic model in ABAQUS was also improved.

5.2. Relaxation Damage Constitutive Relationship. The 6element-generalized Maxwell model coupling damage is chosen as the basis to simulate the stress relaxation damage process at different temperatures and constant levels of input strain. 


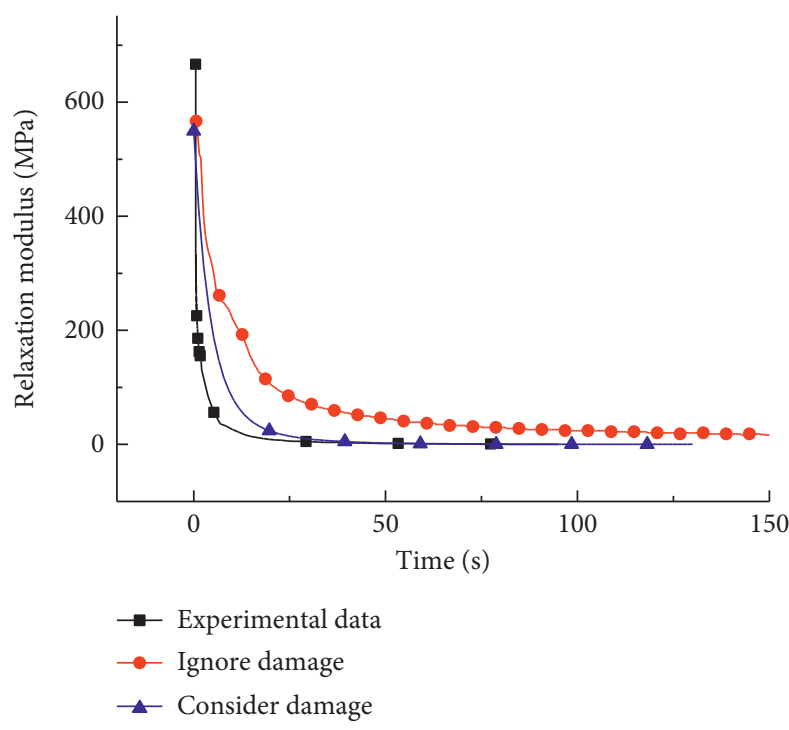

(a)

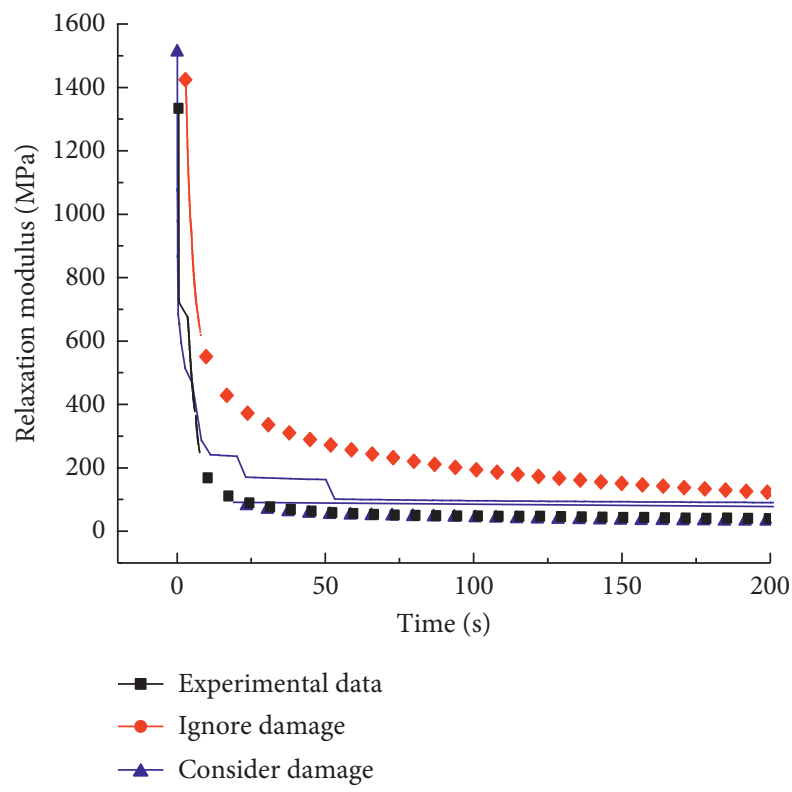

(c)

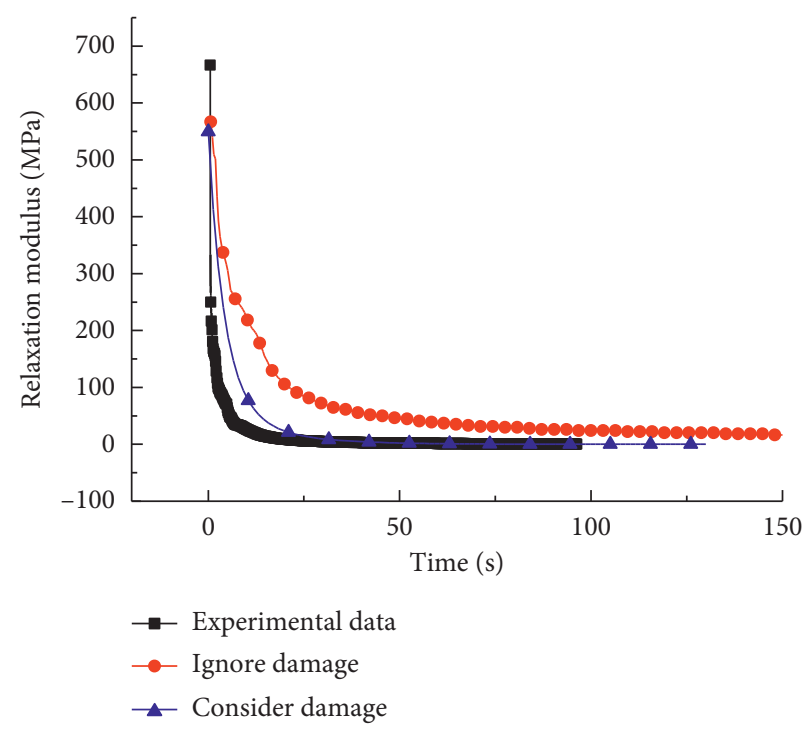

(b)

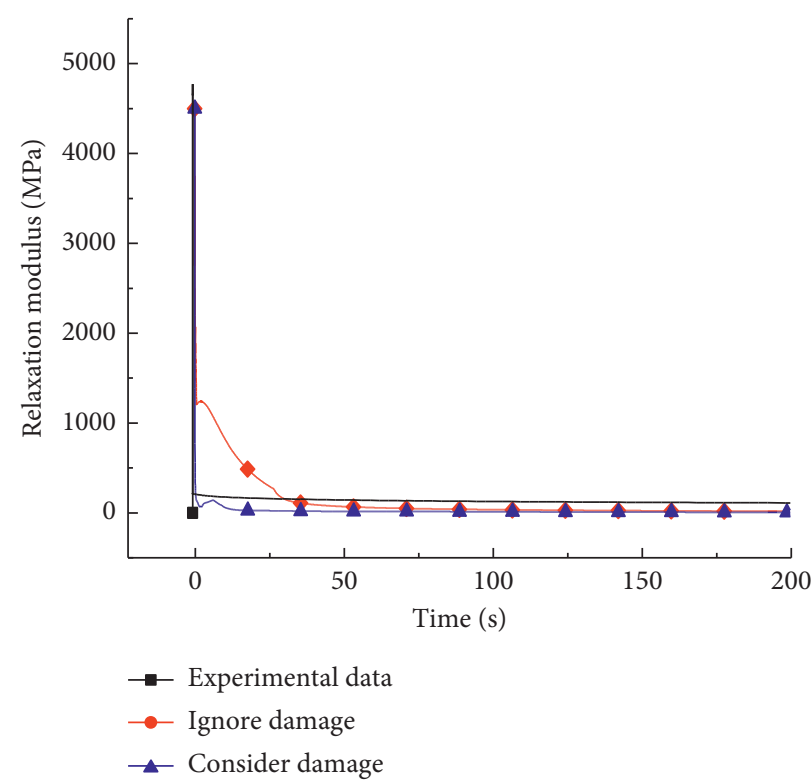

(d)

FIGURE 10: Comparisons of numerical simulation and experimental results. (a) 0.004285. (b) 0.012857. (c) 0.021428 . (d) 0.042857 .

The effective stress is given by [23]:

$$
\tilde{\sigma}_{i j}=\frac{\sigma_{i j}}{1-D}
$$

where $\tilde{\sigma}_{i j}$ is the effective stress tensor $(\mathrm{MPa}), \sigma_{i j}$ is the Cauchy stress tensor (MPa), and $D$ is the damage factor.

The damage factor $D$ is in line with the Weibull distribution:

$$
D=\int_{\gamma}^{\varepsilon} \frac{n}{m}(x-\gamma)^{n-1} e^{-(\varepsilon-\gamma)^{n} / m} d x=1-e^{-(\varepsilon-\gamma)^{n} / m},
$$

where $m$ and $n$ are model parameters and $\gamma$ is the threshold of damage.

Substituting (3) into (2), the relaxation modulus is obtained:

$$
E(t)=\frac{\sigma(t)}{\varepsilon_{0}}=e^{-(\varepsilon-\gamma)^{n} / m}\left(\sum_{i=1}^{n} E_{i} e^{-t / \tau_{i}}\right) .
$$

By (6), the damage thresholds can be obtained through uniaxial compression relaxation experiments. The damage thresholds corresponding to the constant levels of input strain of the uniaxial compression tests are calculated at the loading rate of $50 \mathrm{~mm} / \mathrm{min}$, as shown in Table 3 .

5.3. Establishing of a 3-D Solid Model. ABAQUS, powerful and easily operated finite element software, is well equipped to address the problems of geometric nonlinear materials, nonlinear stress loads, boundary conditions, and nonlinear 
contact. Therefore, it was used to simulate the relaxation process of the asphalt mixtures. The model size is consistent with the specimen in the relaxation test, that is, $30 \times 35 \times 70 \mathrm{~mm}^{3}$. To better simulate the test process, two cylinders with a diameter of $80 \mathrm{~mm}$ and a thickness of $30 \mathrm{~mm}$ were established after setting up the specimen model, to simulate the pressure head and the base, as shown in Figure 8.

5.3.1. Material Parameters. The experimental data were fitted to obtain the parameters for the Prony series of the HVAS at $15^{\circ} \mathrm{C}$, as listed in Table 4 .

5.3.2. Nonlinear Contact Model. In the relaxation test, the contact process has nonlinear characteristics. Therefore, the contact and the friction on the interface should be considered to better simulate the reaction test process. The Coulomb friction model is usually chosen when studying contact problems involving friction in solid mechanics. In the simplified model of static linear elasticity, this law is generally considered together with the unilateral contact model which describes the possible separation of the body from the contact surface (or a rigid foundation) and the absence of penetration of the body into the surface. The interface mechanical behaviour described by the Coulomb contact model is consistent with the relaxation test, so it was used to control the interlayer contact. The nonlinearity of interlayer contact is more obvious when the friction coefficient is less than 0.6 , so 0.5 is taken as the friction coefficient. The relationship between the shearing stress and the normal stress of the Coulomb friction model is shown in Figure 9. The constitutive model of contact element uses the elastic Coulomb friction model, and the relationship between the shearing stress and the normal stress is defined as

$$
\begin{cases}\tau=K_{S} \omega & \omega<\omega_{S} \\ \tau=\mu p & \omega \geq \omega_{S},\end{cases}
$$

where $\tau$ is the shearing stress, $p$ is the normal stress, $\omega$ is the relative displacement between the contact surface, $\omega_{S}$ is the relative displacement of elastic limit, and $\mu$ is the friction coefficient between the surfaces.

5.4. Results and Analysis. The relaxation stress data of the HVAS were obtained in the RPT file format. The stress relaxation curves corresponding to the constant levels of input strains are shown in Figure 10.

As shown in Figure 10, the relaxation modulus obtained by the numerical simulation has a relatively good agreement with the relaxation tests. Especially, taking into account the damage modulus, the difference of the relaxation modulus is obvious at the inflection point of the L-shaped curve. This proves that the damage has obvious effect on the relaxation characteristics of the HVAS.

After taking into account the damage modulus, the simulation values provide a better approximation for the experimental data. There is still a minor deviation between the simulation result and the experimental value at the inflection point of the relaxation modulus curve because a linear interpolation was performed as the data were calculated by ABAQUS, and if the data density is increased, the fitting degree will be further improved.

Results show that the numerical method which takes into account the damage provides a better approximation for the experimental data over almost the whole range of the curve which illustrates that the USDFLD subroutine could effectively predict the relaxation damage process of asphalt mixtures and provide new support for crack control of asphalt pavements.

\section{Conclusions}

The effects of temperatures, loading rates, and constant levels of input strain on relaxation properties by the uniaxial compression tests were investigated. The uniaxial compression tests were employed to determine the relaxation moduli. In order to obtain reliable and reasonable test results, the size of specimens were designed and the constant levels of input strain were defined to ensure that the initial stages of the compression tests were linear elastic. The GMM is used to determine the viscoelastic responses, the Weibull distribution function is used to characterize the damage of the HVAS and its evolution, and the modified GMM is a coupling of the two models. The modified GMM was implemented through a secondary development with the USDFLD subroutine to analyze the relaxation damage process and improve the linear viscoelastic model in ABAQUS. Basing on the findings, the following conclusions can be made:

(1) The relaxation response was significant and similar within the temperature range from $-25^{\circ} \mathrm{C}$ to $15^{\circ} \mathrm{C}$. The relaxation modulus of the HVAS has an L-shaped curve over a wide range of time; the modulus decreases sharply in the first half of the curve and then remains nearly constant in the second half of the curve. The L-shaped curve agrees with the relaxation properties very well.

(2) The peak point of the relaxation modulus is highly influenced by the loading rate in the first half of the L-shaped curve, while the relaxation modulus is almost constant in the second half of the curve. When the input strain is small, the peak point of relaxation modulus increases proportionally to the loading rate because the material is in the elastic stage. However, when the input strain is larger, the peak point does not increase proportionally to the loading rate.

(3) In the first half of the L-shaped curve, the relaxation modulus increases with the input strain (Figures 4 (a)-4(d)). However, the peak point of the relaxation modulus decreases with a higher input strain because the larger input strain brings about more damage in the material.

(4) It is evident that the curve for the relaxation property slows down significantly at low temperature, which 
leads to damage and even splitting, so some tests could not be completed. The relaxation modulus is highly sensitive to the temperature, and the failure occurs earlier at low temperatures. It is suggested that for the HVAS relaxation tests, the temperature should be no less than $-15^{\circ} \mathrm{C}$.

(5) Results show that the numerical method which takes into account the damage provides a better approximation for the experimental data over almost the whole range which illustrates that the USDFLD subroutine can effectively predict the relaxation damage process of asphalt mixtures and provide new support for crack control of asphalt pavements.

\section{Conflicts of Interest}

The authors declare that they have no conflicts of interest.

\section{Acknowledgments}

This research was performed at the Shenyang Jianzhu University and Institute of Transportation Engineering of Zhejiang University. The research is funded by the National Natural Science Fund (51478276) and the Natural Science Foundation of Liaoning Province (20170540770).

\section{References}

[1] M. Shi-bu and H. Song, "Analysis on top-down cracks and its stress intensity factor of semi-rigid pavement," Western China Communications Science \& Technology, vol. 6, pp. 22-26, 2015.

[2] J. C. Maxwell, "On the dynamical theory of gases," Philosophical Transactions of the Royal Society of London, vol. 157, pp. $49-88,1867$.

[3] A. Stimilli, A. Virgili, F. Canestrari, and H. U. Bahia, "Estimation of low-temperature performance of recycled asphalt mixtures through relaxation modulus analysis," Cold Regions Science and Technology, vol. 133, pp. 36-45, 2017.

[4] Y. Wu, J. Shi, Q. Xiao et al., "1H-NMR relaxation and application study of evaporatable water in foamed asphalt," in Proceedings of Geo-China International Conference, pp. 163171, Shandong, China, July 2016.

[5] Q. Fu, Y. J. Xie, D. T. Niu et al., "Integrated experimental measurement and computational analysis of relaxation behavior of cement and asphalt mortar," Construction \& Building Materials, vol. 120, pp. 137-146, 2016.

[6] Y. Wang, Y. Xiao, C. Zheng et al., "Using two-component epoxy resin for asphalt pavement applications-part b: stiffness and relaxation electrical and control engineering \& materials science and manufacturing," in Proceedings of Joint Conferences of the 6th (ICECE2015) and the 4th (ICMSM2015), pp. 519-525, Shanghai, China, August 2016.

[7] S. A. Forough, F. M. Nejad, and A. Khodaii, "Comparing various fitting models to construct the tensile relaxation modulus master curve of asphalt mixes," Road Materials and Pavement Design, vol. 7, p. 15, 2016.

[8] I. L. Hopkins and R. W. Hamming, "On creep and relaxation," Journal of Applied Physics, vol. 28, no. 8, pp. 905-909, 1957.

[9] B. Chen and J. Liu, "Experimental study on AE characteristics of three-point-bending concrete beams," Cement \& Concrete Research, vol. 34, no. 3, pp. 391-397, 2004.
[10] Y. Xiaoqing, "A damaging model of jointed rock under coupled action of freezing and thawing," Chinese Journal of Rock Mechanics and Engineering, vol. 8, pp. 1602-1611, 2015.

[11] X. Fan and G. Xu, "Evaluation method of remaining fatigue life for crane based on the acquisition of the equivalent load spectrum by the artificial neural network," Journal of Mechanical Engineering, vol. 47, no. 20, pp. 69-74, 2011.

[12] X. Ma, ABAQUS6.11 Finite Element Analysis Step by Step, Tsinghua University Press, Beijing, China, 2013.

[13] M. Yang, Development and Application of User-Defined Material Subroutine in ABAQUS Software, Huazhong University of Science and Technology, Wuhan, China, 2005.

[14] K. Fu, "The secondary development of modified burgers creep model based on ABAQUS general software," Highway Engineering, vol. 3, pp. 132-137, 2008.

[15] Z. Chuanjiang, Research on Creep Damage Properites and Constitutive Model for High Viso-Elastic Asphalt Mastic, M.S. dissertation, Vol. 12, Shenyang Jianzhu Universtiy, Shenyang, China, 2014.

[16] JTG E20-2011, Standard Test Methods of Bitumen and Bituminous Mixtures for Highway Engineering, Communications Press, Beijing, China, 2011.

[17] T. Kunyun, Research on the Deformation Characteristics and Gas Seepage Rule of Coal Body Loaded by High Pressure Water, China University of Mining and Technology, Beijing, China, 2014.

[18] L. F. Walubita, Comparison of Fatigue Analysis Approaches for Predicting Fatigue Lives of Hot-Mix Asphalt Concrete (HMAC) Mixtures, Ph.D. thesis, Texas A \& M University, College Station, TX, USA, 2006.

[19] L. Robert and G. U. Fan, "Characteristics of undamaged asphalt mixtures in tension and compression," International Journal of Pavement Engineering, vol. 19, no. 3, pp. 192-204, 2017.

[20] H. Zhang, Mechanism Analysis of the Differences of Asphalt Fatigue Damage Under Stress and Strain Control Mode, Harbin Institute of Technology, Harbin, China, 2014.

[21] F. Canestrari, A. Stimilli, H. U. Bahia, and A. Virgili, "Pseudovariables method to calculate HMA relaxation modulus through low-temperature induced stress and strain," Materials \& Design, vol. 76, pp. 141-149, 2015.

[22] M. B. Boubaker, "Finite element simulation of the slumping process of a glass plate using 3D generalized viscoelastic Maxwell model," Journal of Non-Crystalline Solids, vol. 9, p. 14, 2014.

[23] Y. N. Rabotnov, Creep of Structural Elements, Nauka, Moscow, Russia, 1996. 


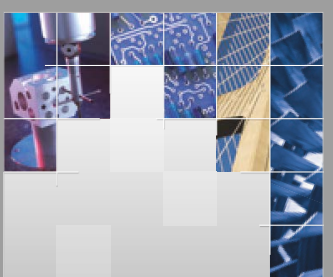

\section{Enfincering}
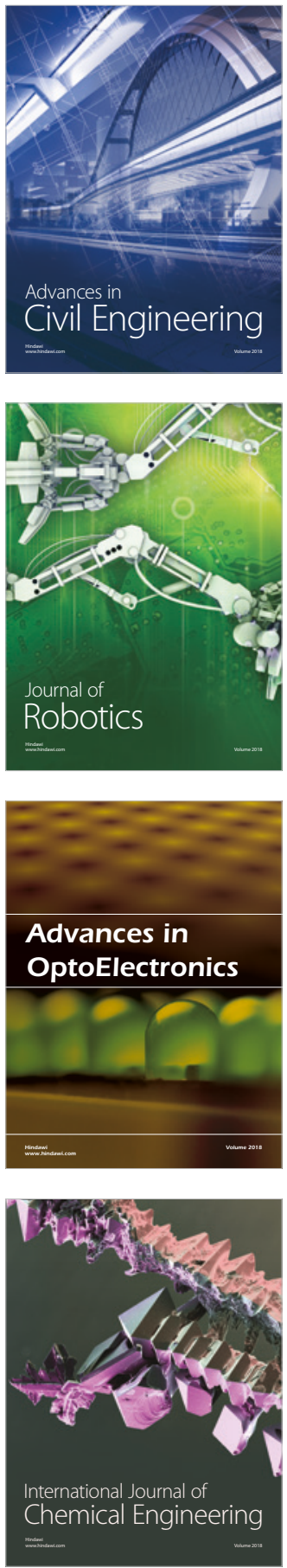

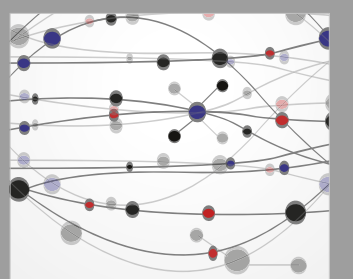

\section{Rotating \\ Machinery}

The Scientific World Journal

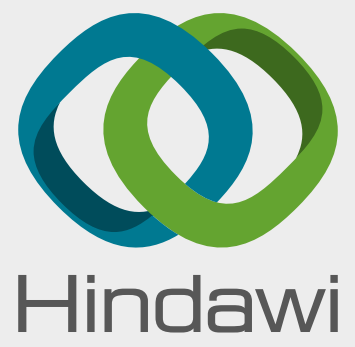

Submit your manuscripts at

www.hindawi.com
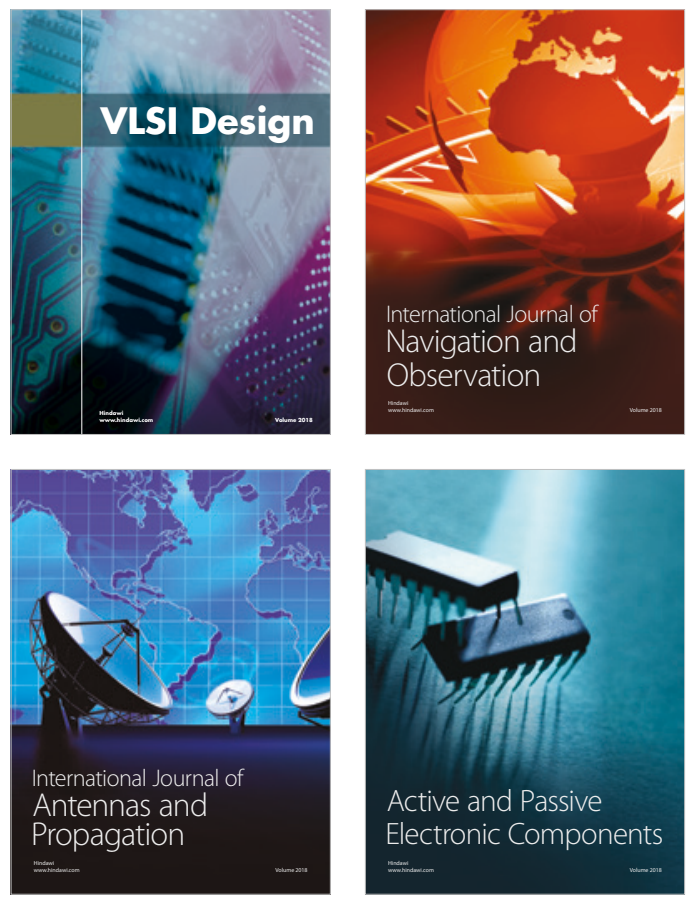
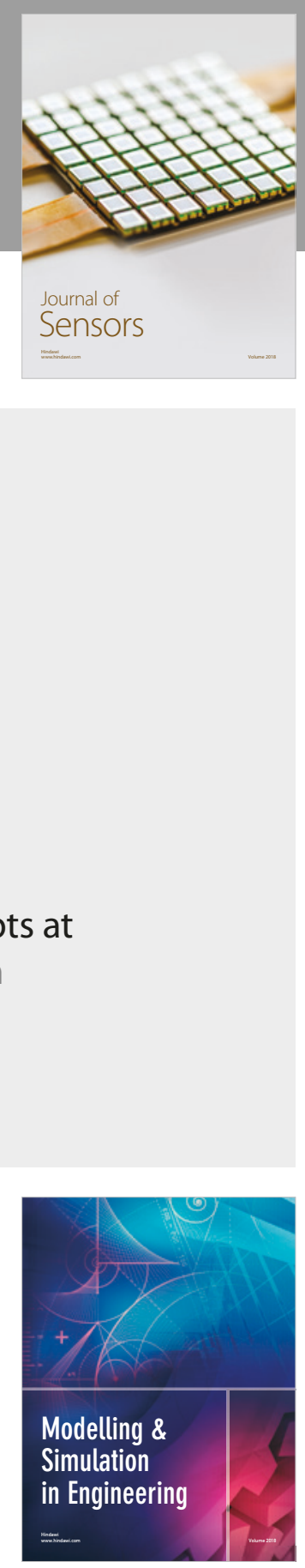

\section{Advances \\ Multimedia}
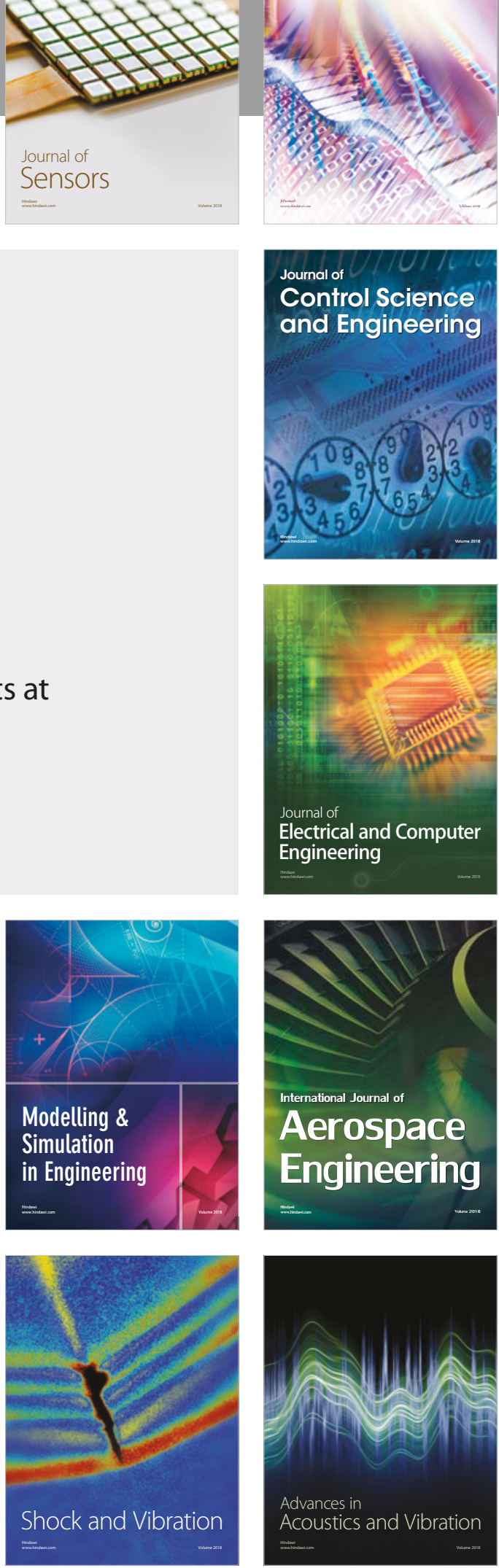